\title{
Comparative study of effectiveness of Papanicolaou smear and visual inspection using acetic acid and visual inspection using Lugol's iodine for screening of premalignant and malignant lesions of cervix
}

\author{
Apra Attri*, Sita Thakur, Ashok Verma, Suman Singh, Priyanka Sharma
}

Department of Obstetrics and Gynecology, Rajendra Prasad Government Medical College, Kangra at Tanda, Himachal Pradesh, India

Received: 07 May 2020

Accepted: 30 May 2020

*Correspondence:

Dr. Apra Attri,

E-mail: apra.attri@gmail.com

Copyright: () the author(s), publisher and licensee Medip Academy. This is an open-access article distributed under the terms of the Creative Commons Attribution Non-Commercial License, which permits unrestricted non-commercial use, distribution, and reproduction in any medium, provided the original work is properly cited.

\section{ABSTRACT}

Background: In developing and resource-limited countries alternative screening methods like VIA, VILI, and Pap smear are used in detection of premalignant and malignant lesions of cervix. The aim of our study was to compare the efficacies of VIA, VILI, and Pap smear in detection of premalignant and malignant lesions of cervix.

Methods: The study was conducted for a period of one year in the department of obstetrics and gynaecology, Dr. Rajendra Prasad Government Medical College, Kangra at Tanda, Himachal Pradesh. Women who attended the outdoor patient department of obstetrics and gynecology were subjected to collection of Pap Smear, VIA followed by VILI and a thorough pelvic examination.

Results: Among the 350 women studied, 59 women (16.9\%) had abnormal VIA, 64 women (18.2\%) had abnormal VILI. On pap smear, 10 women were reported as ASCUS, 11 as L-SIL and 1 as H-SIL. Cervical biopsy was done in 98 women, out of which 70 had one or more abnormality on VIA, VILI, or Pap, and 28 women who had normal results. Sixteen women (16.3\%) reported as CIN-1 and 2 women (2.07\%) as CIN-3. VIA and VILI had a higher sensitivity as compared to pap. However, pap was more specific. The PPV of pap was also much higher as compared to VIA and VILI, whereas there was no difference in NPV of the three.

Conclusions: Authors observed that VIA presented the best sensitivity (88.8\%), followed by VILI (83.3\%), and Pap (72.2\%). Pap smear had the highest specificity of $97.2 \%$. The positive predictive value of Pap was higher as compared to VIA and VILI, whereas there was no difference in NPV of the three. VIA and VILI have good sensitivity, with reasonable specificity and because of their cost effectiveness and ease of availability, these can be an alternative screening modality for cervical cancer screening.

Keywords: Cervical cancer, Pap smear, Visual inspection with Lugol's iodine, Visual inspection with acetic acid

\section{INTRODUCTION}

Cervical cancer is a public health problem especially in developing countries like India, so much so that India alone accounts for one-quarter of the worldwide burden of cervical cancers. ${ }^{1}$ Cervical cancer disproportionately affects women in less-developed countries due to the logistic difficulties of establishing or maintaining comprehensive, cytology-based screening campaigns in low resource settings. ${ }^{2}$ The global estimate for cervical cancer burden in 2008 was 530, 232 new cases. ${ }^{3}$ HPV vaccination and cervical cancer screening have been demonstrated to be effective in prevention of carcinoma cervix in developed countries, but these methods are too expensive for use in developing countries. ${ }^{4}$ In contrast to developed countries, cervical cancer ranks 2nd amongst cancers in women of developing countries, with approximately 445,000 new cases per year. ${ }^{5}$ India's 
cervical cancer age standardised incidence rate $(30.7 / 100,000)$ and age standardised mortality rate $(17.4 / 100,000)$ are the highest in south central Asia, and it accounts for $26.1-43.8 \%$ of all cancers in Indian women. ${ }^{6}$ Most cervical cancer diagnoses occur in developing countries, where cases are detected in later stages and with poor prognosis. An important reason for the high incidence of cervical cancer in developing countries is the lack of effective screening programmes to detect precancerous lesions, and treating them before they progress to invasive cancer. A screening test is a simple, cost effective and sensitive test that can be applied to large numbers of apparently healthy individuals; a diagnostic test, on the other hand, confirms a disease in symptomatic individuals or in individuals at high risk. ${ }^{7}$

However, most women in developing and resourcelimited countries do not have the access to the same methods of cervical cancer screening as women in developed countries. Cytology based screening programmes have reduced the disease burden in high income countries, but these require well trained personnel and adequate infrastructure to manage women with positive test results. Though cervical cytology (Pap smear) remains the most widely used screening test for cervical cancer, a high coverage of the population is hard to attain by the Pap smear approach. Thus, there is a need for inexpensive prevention methods to detect cervical pre-cancers and cancers. ${ }^{8}$ For cervical cancer screening to be successful in resource-limited settings, the screening test, diagnosis, and treatment must either be provided onsite or in clinics accessible to the majority of women at risk. ${ }^{9}$

Other alternative screening methods are therefore used. Visual inspection with Lugol's iodine (VILI) of the cervix is based on the principle that normal squamous epithelium contains glycogen, and since iodine is glycophillic, it is taken up by the epithelium which in turn becomes mahogany brown. In case of malignant and premalignant cells, the epithelium appears yellow brown (in case of partial uptake) and mustard yellow (in case of no uptake). ${ }^{10}$

In visual inspection with acetic acid (VIA), 3-5\% acetic acid solution is applied followed by inspection of the cervix with a halogen lamp after 1 minute. Acetowhite reaction is seen if the epithelial cells have a high nucleocytoplasmic ratio. In case of malignant and premalignant cells there is a high protein content, which gets coagulated on application of acetic acid. The coagulated protein reflects light and appears white. ${ }^{3}$ No screening test is $100 \%$ specific. Majority of studies involving Pap smear and visual inspection using acetic acid or Lugol's iodine have taken place in South India. Keeping in view the topographical conditions of Himachal Pradesh, there is a paucity of research in North India. Hence thihs study was to compare the efficacies of VIA, VILI, and Pap smear in detection of premalignant and malignant lesions of cervix.

\section{METHODS}

The study was conducted for a period of one year $\left(1^{\text {st }}\right.$ February 2018 to $31^{\text {st }}$ January 2019) in the department of obstetrics and gynecology, Dr. Rajendra Prasad Government Medical College, Kangra at Tanda, Himachal Pradesh.

\section{Inclusion criteria}

\section{- $\quad$ Age 21-65}

- Intact uterus (no previous surgery of the cervix or corpus)

- Had no history of abnormal Pap test in the past year

- No history of vaginal pessary or examination in the past 3 days

- Had abstained from intercourse for 3 days prior to examination

- Had no confirmed/suspected immune-suppression (HIV, corticosteroids, chemotherapy, chronic diseases).

\section{Exclusion criteria}

- Women who refused to participate in the study

- Known cases of Ca cervix.

Women who attended the outdoor patient department of obstetrics and gynecology at Dr. Rajendra Prasad Government Medical College, Kangra at Tanda were counselled and explained the procedure that was performed. Those who consented were subjected to collection of Pap smear, VIA followed by VILI and a thorough pelvic examination. Women with one or more abnormal results were subjected to colposcopy in the next sitting. The decision to take a histological specimen was based upon the Pap smear result and colposcopy.

\section{Cervical cytology}

Conventional Pap smears was taken using the Ayre spatula and endocervical brush, fixed in 95\% ethanol, stained by the modified Papanicolaou method and final cytological diagnosis was issued using the Bethesda system as follows:

- Specimen type: conventional Pap smear

- Specimen adequacy: adequate/inadequate

Smear

- Satisfactory for evaluation

- Unsatisfactory

\section{Visual inspection using acetic acid}

After the collection of the samples for the Pap test, freshly prepared $5 \%$ acetic acid was applied to the cervix, which was visually examined after 1 minute using a 
bright lamp. The observations were recorded in the proforma.

\section{Visual inspection using Lugol's iodine}

Following the completion of VIA, the cervix was stained with Lugol's iodine and observations were recorded graphically.

\section{Colposcopy}

Colposcopy was performed after an abnormal VIA/VILI or a positive Pap smear, at the $2^{\text {nd }}$ appointment. Careful examination of the cervix and transformation zone was carried out after application of 5\% acetic acid on the entire cervix.

\section{Cervical biopsies}

When either of the three screening tests or colposcopy had a positive finding, biopsies were taken. Ten percent of the women, who had normal VIA, VILI and Pap reports, also underwent cervical biopsy. Tissue samples were fixed in formalin, and sent for histopathological examination to the pathology department at Dr. Rajendra Prasad Government Medical College, Kangra at Tanda.

\section{Statistical analysis}

The data was entered in the excel sheet and analysed using statistical software. The sensitivity, specificity, positive predictive value (PPV) and negative predictive value (NPV) were then calculated.

\section{RESULTS}

\section{Speculum and per-vaginum findings}

Among the 350 women studied, 267 women (76.3\%) had no abnormal cervical appearance on speculum examination, while 81 women $(23.1 \%)$ had cervical erosions or ectopy. Similarly, on per vaginum, there was bleeding on touch from cervix in 12 women $(3.4 \%)$. There were incidental findings of uterine fibroids and adnexal masses in 30 women $(8.5 \%)$ as shown in Table 1.

Table 1: Speculum and per-vaginum examination findings.

\begin{tabular}{|lll|}
\hline Speculum examination & Number & Percentage \\
\hline Cervix and vagina healthy & 267 & $76.3 \%$ \\
\hline Cervical ectopy and erosion & 81 & $23.1 \%$ \\
\hline Cervix unhealthy, suspicious & 2 & $0.6 \%$ \\
\hline Total & 350 & $100.0 \%$ \\
\hline P/V & 12 & $3.4 \%$ \\
\hline Cervix bleeds on touch & 12 & $8.5 \%$ \\
\hline $\begin{array}{l}\text { Uterine fibroids and adnexal } \\
\text { masses }\end{array}$ & 30 & $100.0 \%$ \\
\hline Total & 350 & \\
\hline
\end{tabular}

\section{VIA, VILI and Pap smear}

Among the 350 women studied, 59 women (16.9\%) had abnormal VIA, 64 women (18.2\%) had abnormal VILI. On pap smear, 10 women were reported as ASCUS, 11 as L-SIL and 1 as H-SIL. There were no glandular abnormalities. The results are shown in Table 2.

Table 2: VIA, VILI, Pap examination findings.

\begin{tabular}{|lll|}
\hline VIA & Number & Percentage \\
\hline AAT -ve (no abnormality) & 291 & $83.1 \%$ \\
\hline AAT +ve (abnormality +) & 59 & $16.9 \%$ \\
\hline Total & 350 & $100.0 \%$ \\
\hline VILI & & \\
\hline VILI -ve (no abnormality) & 286 & $81.6 \%$ \\
\hline VILI +ve (abnormality +) & 64 & $18.2 \%$ \\
\hline Total & 350 & $100.0 \%$ \\
\hline PAP & 269 & $76.8 \%$ \\
\hline NILM & 59 & $16.9 \%$ \\
\hline Inflammatory & 10 & $2.9 \%$ \\
\hline $\begin{array}{l}\text { Epithelial cell } \\
\text { abnormalities: ASCUS }\end{array}$ & 0 & $0 \%$ \\
\hline ASC-H & 11 & $3.1 \%$ \\
\hline LSIL & 1 & $0.3 \%$ \\
\hline HSIL & 0 & $0 \%$ \\
\hline $\begin{array}{l}\text { Glandular cell } \\
\text { abnormalities }\end{array}$ & 350 & $100 \%$ \\
\hline Total &
\end{tabular}

\section{Cervical biopsy}

Among the 350 women studied, cervical biopsy was done in 98 women, out of which 70 had one or more abnormality on VIA, VILI, or Pap, and 28 women who had normal results. Sixteen women $(16.3 \%)$ reported as CIN-1 and 2 women $(2.07 \%)$ as CIN-3, as shown in Table 3.

Table 3: Cervical biopsy findings.

\begin{tabular}{|lll|}
\hline Biopsy & Number & Percentage \\
\hline Normal & 80 & $81.6 \%$ \\
\hline CIN-1 & 16 & $16.3 \%$ \\
\hline CIN-2/3 & 2 & $2.07 \%$ \\
\hline CIS/Invasive Ca & 0 & $0 \%$ \\
\hline Total & 98 & $100 \%$ \\
\hline
\end{tabular}

Table 4 shows a comparative analysis of clinical cervical appearance and VIA, VILI, Pap and cervical biopsy results.

On per speculum examination, out of the 267 women who had a normal looking cervix, 2 had abnormal VIA and 1 had abnormal VILI.

Pap report showed ASCUS in 2 of these patients. The histopathology reports of these patients were normal. 
Table 4: VIA, VILI, Pap and cervical biopsy results.

\begin{tabular}{|llllllll|}
\hline \multirow{2}{*}{ Cervical appearance } & VIA & VILI & \multicolumn{2}{c|}{ Pap smear abnormality } & \multicolumn{2}{c|}{$\begin{array}{c}\text { Cervical Biopsy } \\
\text { abnormality }\end{array}$} \\
& $\begin{array}{l}\text { Abnormality } \\
\text { Abnormality }\end{array}$ & ASCUS & L-SIL & H-SIL & \multicolumn{2}{c|}{ CIN-1 } & CIN-2/3 \\
\hline Normal (267) & 2 & 1 & 2 & 0 & 0 & 0 & 0 \\
\hline Ectopy/erosion (81) & 55 & 61 & 8 & 11 & 0 & 16 & 0 \\
\hline Unhealthy (2) & 2 & 2 & 0 & 0 & 1 & 0 & 2 \\
\hline
\end{tabular}

Table 5: Evaluation of VIA, VILI and Pap smear in relation to cervical biopsy.

\begin{tabular}{|lll|}
\hline Total=350 & $\begin{array}{l}\text { Biopsy } \\
\text { significant } \\
\text { lesion }(\mathbf{n = 1 8})\end{array}$ & $\begin{array}{l}\text { Biopsy } \\
\text { normal } \\
(\mathbf{n = 3 3 2})\end{array}$ \\
\hline VIA + 59 & 16 & 43 \\
\hline VIA - 291 & 2 & 289 \\
\hline VILI + 64 & 15 & 49 \\
\hline VILI- 286 & 3 & 283 \\
\hline $\begin{array}{l}\text { PAP + 22 (ASCUS, } \\
\text { L-SIL, H-SIL) }\end{array}$ & 13 & 9 \\
\hline PAP - 328 & 5 & 323 \\
\hline
\end{tabular}

Whereas, out of the 81 patients who had ectopy or erosions on per speculum examination, 61 had an abnormal VIA/VILI, 8 had Pap reports of ASCUS, and 11 had L-SIL, out of which, 16 had CIN-1 on histopathology report and no one had CIN-2/3. Two cases that had unhealthy looking cervix, and both had abnormal VIA as well as VILI. Pap smear report was H-SIL in 1 case. The histopathology report of both the cases was CIN 2/3.

Table 5 shows that out of the 350 women studied, 59 women, who had abnormal VIA, reported biopsy significant lesion in 16, and normal biopsy findings in 43 . VIA failed to pick up 2 women, who were diagnosed on biopsy. Similarly, 64 women who had abnormal VILI reported biopsy significant lesion in 15, and normal biopsy findings in 49 . VILI failed to pick-up 3 women, who were diagnosed on biopsy. Whereas, 22 women who had abnormal Pap reports, had biopsy significant lesion in 13, and normal biopsy findings in the remaining 9. Pap failed to pick-up 5 women, who were diagnosed on biopsy.

Sensitivity, specificity, positive predictive value, and negative predictive values

In the present study, VIA had a sensitivity of $88.8 \%$, specificity of $87 \%$, PPV of $27.1 \%$ cases, and NPV of 99.3\%. Similarly, VILI had a slightly sensitivity of $83.3 \%$, specificity of $85.2 \%$, PPV of $23.4 \%$, and NPV of $98.9 \%$. However, Pap smear had a sensitivity of $72.2 \%$, but specificity was higher $(97.2 \%)$. It had higher PPV of $59.1 \%$ and NPV of $97.48 \%$.
Table 6: Sensitivity, specificity, PPV, and NPV.

\begin{tabular}{|ll|ll|}
\hline $\begin{array}{l}\text { Diagnosis of low grade } \\
\text { lesion }\end{array}$ & VIA & VILI & $\begin{array}{l}\text { Pap } \\
\text { smear }\end{array}$ \\
\hline Sensitivity & 88.8 & 83.3 & 72.2 \\
\hline Specificity & 87 & 85.2 & 97.2 \\
\hline Positive predictive value & 27.1 & 23.4 & 59.1 \\
\hline Negative predictive value & 99.3 & 98.9 & 97.48 \\
\hline
\end{tabular}

Table 6 shows sensitivity, specificity, positive predictive value, and negative predictive value of Pap smear, VIA, and VILI for diagnosing premalignant and malignant lesions of cervix (LSIL/HSIL).

Table 7: Management of all cases.

\begin{tabular}{|lll|}
\hline Treatment & Number & Percentage \\
\hline Not required-follow-up & 332 & $94.8 \%$ \\
\hline Cryo-cautery & 16 & $4.5 \%$ \\
\hline Hysterectomy & 2 & $0.57 \%$ \\
\hline Total & 350 & $100 \%$ \\
\hline
\end{tabular}

From the table it is observed that VIA and VILI had a higher sensitivity as compared to pap. However, pap was more specific. The PPV of pap was also much higher as compared to VIA and VILI, whereas there was no difference in NPV of the three.

\section{Management}

Out of the 350 women studied, 332 women (94.8\%) required no treatment and were scheduled for routine follow up. Cervical cryocautery was done in a total of 16 women $(4.5 \%)$ after histopathology report of CIN-1 on cervical biopsy. Two women $(0.57 \%)$, who had cervical biopsy reports of $\mathrm{CIN} 2 / 3$, expressed their inability to come for follow up as they belonged to remote areas, and underwent hysterectomy as shown in Table 7.

\section{DISCUSSION}

PAP smear was taken in all the 350 women enrolled in the study. In $77.4 \%$ (231) women, the smears reported NILM, $16.9 \%$ (59 women) as inflammatory. Smear and epithelial cell abnormalities were noted in $6.3 \%$ (10 as ASCUS, 11 as LSIL and HSIL was reported in 1) of the participants. Yagnik et al had $90 \%$ normal smears and 
$8.1 \%$ smears with epithelial cell abnormalities $(1.7 \%$ as ASCUS, $2.6 \%$ LSIL, and $3.8 \%$ as HSIL). ${ }^{11}$ Sinha S et al found $31.5 \%$ lesions as inflammatory, $5 \%$ as LSIL and $3.5 \%$ smears were HSIL. ${ }^{12}$ Ghosh $\mathrm{P}$ et al reported that pap smear was positive (ASCUS or worse) in 13 cases (3.71\%), including 10 cases of LSIL and three of HSIL. ${ }^{10}$ The diversity in the results in these studies is due to the differences in the methodology of the studies and different mean age of the participants.

\section{VIA}

In our study, VIA was done in 350 women, out of which it was positive in $16.9 \%$ (59 women). Akinola et al reported $16.2 \%$ positive results, and Goel A et al reported that $12.5 \%$ results were positive. ${ }^{7,8}$ Sangwa-Lugoma et al, found VIA to be positive in $58 \%$ of the cases, whereas Dawood R et al reported $8.6 \%$ cases to be positive. ${ }^{13,14}$

\section{VILI}

In this study, VILI was positive in $18.2 \%$ (64 women). Consul S et al reported $11.43 \%$ cases to be positive, and Yagnik et al reported $13.6 \%$ positive cases. ${ }^{11,15}$ On the other hand, Sangwa-Lugoma et al and Qureshi et al, noted that positive cases accounted for more than $50 \%$ of the tests, the numbers being $54.8 \%$ and $58.36 \%$, respectively. ${ }^{13,16}$

\section{VIA and VILI combined}

In this study, the combined positives of VIA and VILI were 68 women $(19.4 \%)$. Jeyakumar AM et al, reported a similar result (18.3\% positive results). ${ }^{17}$ El-Shalakany et al, found only $9.4 \%$ cases to be positive. ${ }^{18}$

\section{Cervical biopsy}

In this study, cervical biopsies were taken when any test was abnormal and from ten percent of the negative cases. A total of 98 women underwent cervical biopsy (70 from VIA, VILI, or Pap abnormalities + 28 from all negatives). Sixteen women $(16.3 \%)$ reported as CIN-1, two women $(2.07 \%)$ as $\mathrm{CIN}-2 / 3$, and none of the women was found to have invasive carcinoma. Ghosh $\mathrm{P}$ et al, reported $22.4 \%$ as CIN-1 and $6.8 \%$ as CIN-2. ${ }^{10}$ Ottaviano et al found $26 \%$ women as CIN-1. On the contrary, Dawood R et al noted $2 \%$ as CIN-1 and $1 \%$ as CIN-2. ${ }^{14,19}$

\section{VIA versus cervical biopsy}

In this study, VIA had a sensitivity of $88.8 \%$, specificity of $87 \%$, PPV $27.1 \%$, and NPV $99.3 \%$. Ghosh P et al and Dawood R et al reported similar figures for sensitivity (89.47\% and $89 \%$, respectively). ${ }^{10,14}$ Saleh HS et al, and Kalgong et al noted higher sensitivities $(91.3 \%$ and $94.8 \%) .^{20,21}$ Saleh HS et al reported similar specificity to this study, whereas Kalgong et al, reported sensitivity to be $97.1 \% .^{20,21}$ Ghosh P et al reported PPV to be $36.95 \%$, and it was found to be $40.1 \%$ in Saleh HS et al. ${ }^{10,20}$
Kalgong et al, found PPV to be on the higher side $(82.2 .1 \%) .{ }^{21}$ Ghosh $\mathrm{P}$ et al, reported NPV as $99.3 \%$ and El-Shalakany A et al found it be to $99.6 \% .^{10,18}$

\section{CONCLUSION}

In the present study, authors observed that VIA presented the best sensitivity $(88.8 \%)$, followed by VILI $(83.3 \%)$, and Pap (72.2\%). However, when it comes to specificity, Pap smear had the highest specificity of $97.2 \%$. This was followed by VIA (87\%), and VILI (85.2\%). The positive predictive value of Pap was also much higher as compared to VIA and VILI, whereas there was no difference in NPV of the three. The low PPVs of VIA and VILI obtained in this study (27.1 and $23.4 \%$, respectively) can be improved with skill and experience of the health care provider performing the test.

Thus, VIA and VILI have good sensitivity, with reasonable specificity and because of their cost effectiveness and ease of availability, these direct visual inspection methods can be a tempting alternative screening modality for cervical cancer screening, with the advantage that it can be performed even by a nonspecialist doctor or a paramedical personnel working in the periphery, who are often the first to deal with women who are at a higher risk of developing cervical cancer. Hence, by screening with VIA and VILI, the burden of referral for cytological screening and cervical biopsy could be reduced ultimately leading to substantial gains in the prevention of cervical cancer.

\section{ACKNOWLEDGMENTS}

Authors would like to acknowledges RPGMC, Tanda, HP for providing infrastructure and resources during the study and preparation of the manuscript of this paper.

Funding: No funding sources

Conflict of interest: None declared

Ethical approval: The study was approved by the Institutional Ethics Committee

\section{REFERENCES}

1. Bobdey S, Sathwara J, Jain A, Balasubramaniam G. Burden of cervical cancer and role of screening in India. Indian J Med Paediatr Oncol 2016;37:278-85.

2. Li R, Lewkowitz AK, Zhao F, Zhou Q, Hu S, Qiu H, et al. Analysis of the effectiveness of visual inspection with acetic acid/Lugol's iodine in onetime and annual follow-up screening in rural China. Arch Gynecol Obstet. 2012;285:1627-32.

3. Sankaranarayanan R, Nessa A, Esmy Po, Dangou JM. Visual inspection methods for cervical cancer prevention. Best Pract Res Clin Obstet Gynaecol. 2012;26:221-32.

4. Lee H, Kang Y, Ju W. Cervical cancer screening in developing countries: using visual inspection methods. World J Clin Oncol. 2015;6(6):281-90. 
5. Catarino R, Schafer S, Vassilakos P, Petignat $P$, Arbyn M. Accuracy of combinations of visual inspection using acetic acid or Lugol's iodine to detect cervical precancer: a meta-analysis. BJOG. 2018;125(5):545-53.

6. Mustafa MS, Jindal AK, Singh PMP. Visual Inspection using acetic acid for cervical cancer in low resource settings. MJAFI. 2010;66:382-4.

7. Goel A, Gandhi G, Batra S, Bhambhani S, Zutshi V, Sachdeva P. Visual inspection of the cervix with acetic acid for cervical intraepithelial lesions. Int $\mathbf{J}$ Gynecol Obstet. 2005;88:25-30.

8. Akinola OI, Fabamwo AO, Oshodi YA, Banjo AA, Odusanya O, Gbadegesin A, et al. Efficacy of visual inspection of the cervix using acetic acid in cervical cancer screening: a comparison with cervical cytology. J Obstet Gynaecol. 2007;27(7):703-5.

9. Raifu AO, El-Zein M, Sangwa-Lugoma G, Ramanakumar A, Walter SD, Franco EL. Determinants of cervical cancer screening accuracy for visual inspection with acetic acid (VIA) and Lugol's iodine (VILI) performed by nurse and physician. PLoS ONE. 2017;12(1):1-13.

10. Ghosh P, Gandhi G, Kochhar PK, Zutshi V, Batra S. Visual inspection of cervix with Lugol's iodine for early detection of premalignant and malignant lesions of cervix. Indian $\mathrm{J}$ Med Res. 2012;136(2):265-71.

11. Yagnik AS and Singh R. A prospective study of comparison Pap's smear, vili's test and colposcopy in cervical cancer screening. Int J Med Res Health Sci. 2016;5(4):50-7.

12. Sinha S, Singh V, Mishra B, Singh A. Comparing the efficacy of visual inspection of cervix with acetic acid and Lugol's iodine with Pap smear cytology in screening for cancer cervix. J Curr Res Sci Med. 2018;4:10-6.

13. Sangwa-Lugoma G, Mahmud S, Nasr SH, Liaras J, Kayembe PK, Tozin RR et al. Visual inspection as a cervical cancer screening method in a primary health care setting in Africa. Int $J$ Cancer. 2006;119(6):1389-95.

14. Dawood R, El-Tahmoudy M. Visual inspection techniques versus Pap smear in screening for premalignant and malignant lesions of the cervix in Menoufi a governorate, Egypt. Tanta Med J. 2015;43:108-12.

15. Consul S, Agrawal A, Sharma H, Bansal A, Gutch M, Jain N. Comparative study of effectiveness of Pap Smear versus visual inspection with acetic acid and visual inspection with Lugol's iodine for mass screening of premalignant and malignant lesion of cervix. Indian J Med Paediatr Oncol. 2012;33:161-5.

16. Qureshi S, Das V, Zahra F. Evaluation of visual inspection with acetic acid and Lugol's iodine as cervical cancer screening tools in a low-resource setting. Trop Doct. 2010;40(1):9-12.

17. Jeyakumar AM, Mohanapu S. A comparison of cervical cancer screening methods: pap smear, liquid based cytology and VIA VILI. Int J Reprod Contracept Obstet Gynecol. 2019;8(5):1738-44.

18. El-Shalakany A, Hassan SS, Ammar E, Ibrahim MA, Salam MA, Farid M. Direct visual inspection of the cervix for the detection of premalignant lesions. J Low Genit Tract Dis. 2004;8(1):16-20.

19. Ottaviano M, Torre PL. Examination of the cervix with the naked eye using acetic acid test. Am J Obstet Gynecol. 1982;143(2):139-43.

20. Saleh HS, El Hameid AAA, Mowafy HE, Sherif HE, Abdelsalam WA. Visual inspection of the cervix with (acetic acid or Lugol's iodine) for cervical cancer screening. Cancer. 2006;1:111.

21. Kalgong G, Kamdje N, Tagne S, Amvene MBO, Nangue C. Cervical cancer screening with visual inspection with acetic acid and lugol as primary screening test, a comparable result to conventional Pap smear in Northern Cameroon. J Can Sci Res. 2017;2:2-4.

Cite this article as: Attri A, Thakur S, Verma A, Singh S, Sharma P. Comparative study of effectiveness of Papanicolaou smear and visual inspection using acetic acid and visual inspection using Lugol's iodine for screening of premalignant and malignant lesions of cervix. Int J Reprod Contracept Obstet Gynecol 2020;9:2926-31. 